\title{
Analisis Nilai Tambah pada Pengolahan Beras Ketan Menjadi Rengginang
}

\author{
Iffan Maflahah, Asfan, Vina Istianah \\ Teknologi Industri Pertanian, Universitas Trunojoyo Madura \\ iffanmaflahah@gmail.com
}

DOI: https://doi.org/10.21107/rekayasa.v13i1.5745

\begin{abstract}
ABSTRAK
Beras ketan putih disebut dengan (Oryza sativa glutinosa) merupakan salah satu varietas padi yang termasuk dalam family Graminae. Rengginang merupakan makan ringan yang berbahan baku beras ketan namun memiliki bermacam-macm bahan tambahan contohnya rengginang ikan teri, rengginang kerang dan rengginang lorjuk Dengan adanya bahan tambahan tersebut juga akan memberikan nilai tambah terhadap produk olahan beras ketan menjadi rengginang tersebut. Tujuan dari penelitian ini adalah untuk mengetahui nilai tambah dari pengolahan beras ketan menjadi rengginang menggunakan Metode Hayami. Penelitian ini menggunakan metode Hayami. Penelitian ini menghitung nilai tambah dari rengginang ketan, rengginang teri, rengginang kerang dan rengginang lorjuk. Hasil analisis nilai tambah dari produk di UD. Praktis memiliki nilai tambah pada produk rengginang ketan yaitu Rp 5.400, rengginang teri sebesar Rp 9.400, rengginang lorjuk yaitu Rp 30.600 dan rengginang kerang adalah $\mathrm{Rp}$ 15.200. Dan untuk rengginang ketan memiliki rasio nilai tambah yaitu 18,9\% rengginang teri yaitu $24 \%$, rengginang kerang adalah $38,75 \%$ ketiga rengginang tersebut termasuk kategori sedang karena berada diantara 15\%-40\% dan rengginang lorjuk yaitu $47 \%$ termasuk kategori tinggi karena memiliki rasio nilai tambah lebih besar sama dengan $40 \%$.

Kata Kunci : Beras ketan, Analisis Nilai Tambah, Rasio Nilai Tambah.
\end{abstract}

\section{Added Value Analysis at Processing Of Glutinous Rice to be Rengginang}

\section{ABSTRACT}

The white glutinous rice (Oryza sativa glutinosa) is the one of rice variety which is included in the Graminae family. Rengginang is a kind of snack that is made from glutinous rice, but it has a variety of additional ingredients such as anchovy, scallop rengginang and rengginang lorjuk. By the existence of additional ingredients, it will give added value to the processed product of glutinous rice becomes rengginang. The aim of this research is to find out the added value from the processing of glutinous rice becomes rengginang by using the Hayami method. This research uses a Hayami method. This research counts the added value from glutinous rengginang, anchovy rengginang, scallop rengginang, and rengginang lorjuk. The results of the added value from the product in UD, practically it has added values at the product

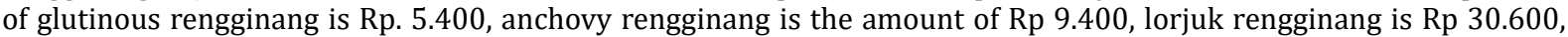
and scallop rengginang is $\mathrm{Rp} 15.200$. And also for glutinous rengginang has the ratio of added value $18,9 \%$ anchovy rengginang $24 \%$, scallop rengginang $38,75 \%$, these three rengginang are included in the moderate category because they are between $15 \%-40 \%$ and rengginang lorjuk is $47 \%$ including the high category because it has the ratio of added value amount of more than $40 \%$. Keywords: Glutinous rice, Analysis of Added Value, the Ratio of Added Value.

\section{PENDAHULUAN}

Beras ketan juga mengandung vitamin (terutama pada bagian aleuron), mineral dan air. Beras ketan merupakan tanaman yang berasal dari Asia yang kini sudah tersebar luas ke seluruh dunia, termasuk Indonesia. Di beberapa negara seperti Laos dan Thailand beras ketan digunakan sebagai makanan pokok, dikarenakan kandungan karbohidratnya yang tinggi (Haryadi, 2006).

Beras ketan putih memiliki potensi yang sangat tinggi di Indonesia sehingga produktivitasnya pun semakin meningkat tiap tahunnya. Berdasarkan data dari Badan Pusat Statistik diketahui bahwa pada tahun 2011 sampai tahun 2015, jumlah ketersediaan beras meningkat dari 10.576 .543 ton menjadi 13.154.967 ton. (Badan Pusat Statistik Provinsi Jawa Timur 2015).

\section{Article History:}

Received: July, 27 th 2019; Accepted: January, $12^{\text {th }} 2020$

ISSN: 2502-5325 (Online) Terakreditasi Peringkat 3 oleh Kementerian Riset, Teknologi dan Pendidikan Tinggi (ARJUNA), berdasarkan Keputusan Direktur Jenderal Penguatan Riset dan Pengembangan No: 23/E/KPT/2019 tanggal 8 Agustus 2019
Produk olahan yang dihasilkan dari beras ketan yaitu olahan manis seperti kue, opak, kue lemper, uli goring dan rengginang. Rengginang merupakan makan ringan yang berbahan baku beras ketan namun memiliki bermacam-macm bahan tambahan contohnya rengginang ikan teri, rengginang kerang dan rengginang lorjuk ketiga rengginang tersebut merupakan produk olahan dari beras ketan dari UD. Praktis.

UD. Praktis adalah Usaha Kecil Menenegah yang didirikan oleh lbu Khotimah pada tahun 2001. UD.Praktis memproduksi makanan tradisisonal yaitu rengginang CAP Jempol. Ada beberapa varian rengginang yang diproduksi yaitu rengginang teri, lorjuk dan kerang. UD. Praktis telah melakukan penjualan tak hanya di Madura namun juga diluar Madura yaitu Jawa Tengah, serta Jawa Barat juga mengenal rengginang sebagai makanan khas

\section{Cite this as:}

Maflahah, I. Asfan, A. Istianah, V. (2020). Analisis Nilai Tambah pada Pengolahan Beras Ketan menjadi Rengginang. Rekayasa, 13(1), 67-70. doi: https://doi.org/10.21107/rekayasa.v13i1.5745 (c) 2020 Author(s) 
Madura. Untuk menambah cita rasa rengginang ditambahkannya bahan tambahana lain diantaranya ikan teri, kerang dan lorjuk. Alasan UD. Praktis menggunakan bahan tambahan tersebut karena melimpahnya bahan tambahan tersebut yaitu ikan teri, kerang dan lorjuk di daerah Kabupaten Sumenep.

Produk rengginang di UD. Praktis memiliki ketiga bahan tambahan yaitu ikan teri, lorjuk dan kerang agar menambah cita rasa dan juga untuk menambah minat konsumen terhadap produk rengginang tersebut. Dengan adanya bahan tambahan tersebut juga akan memberikan nilai tambah terhadap produk olahan rengginang tersebut. Dan juga untuk memberikan varian yang berbeda sehingga konsumen tidak merasa monoton.

Permintaan rengginang begitu meningkat terutama di daerah Madura. Berdasarkan Pusat Statistik dikethaui bahwa pada tahun 2013-2015, jumlah permintaan rengginang di daerah Madura meningkat dari 358.000 ton sampai 561.000 ton (Badan Pusat Statistik Provinsi Jawa Timur 2016)

Suatu perusahaan dengan teknologi yang lebih baik akan meningkatkan produk dengan kualitas yang lebih baik pula, sehingga harga produk olahan akan lebih tinggi dan akhirnya akan memperbesar nilai tambah yang diperolehnya (Suryana, 1995).

\section{METODE PENELITIAN}

Analisis Nilai Tambah dilakukan untuk mengetahui nilai tambah yang terdapat dari pengolahan beras ketan menjadi rengginang di UD. Praktis. kemudian membandingkan nilai tambah tertinggi dari beberapa produk rengginang di UD.Praktis.

Metode AnalisisNilai Tambah yaitu menggunakan Metode Hayami dengan memasukkan data yang ada ke tabel Metode Hayami. Tabel metode Hayami dapat dilihat di Tabel 1.

\section{HASIL DAN PEMBAHASAN}

Hasil dari perhitungan nilai tambah pada pengolahan beras ketan di UID. Praktis diakukan pada beberapa variasi rengginang yaitu rengginang ketan,rengginang teri, rengginang kerang dan rengginang lorjuk dapat dilihat di Tabel 2.

Harga rata-rata bahan baku beras ketan adalah $\mathrm{Rp} 18.500 / \mathrm{kg}$. Sedangkan dengan sumbangan input lain rengginang ketan sebesar $\mathrm{Rp} 4.600 / \mathrm{kg}$, rengginanag teri yaitu Rp 10.500, rengginang lorjuk Rp 14.900 dan untuk rengginang kerang yaitu 6.300. Nilai produk rengginang kerang sebesar $\mathrm{Rp}$ 28.500 , rengginang teri yaitu 38.400 , rengginang lorjuk adalah 64.000 dan rengginang kerang yaitu 40.000. nilai tersebut dihasilkan dari perkalian antra faktor konversi dengan harga produk rata-rata $(\mathrm{Rp} / \mathrm{kg})$. Dan untuk imbalan tenaga kerja rengginang ketan diperoleh dari hasil kali antara koefisien tenaga kerja dengan upah tenaga kerja yaitu sebesar Rp 4.000 dengan presentase terhadap tenaga kerja yaitu sebesar $74 \%$, rengginang teri yaitu upah sebesar Rp 4.000 dan presentase $42,5 \%$, rengginang lorjuk yaitu $\mathrm{Rp} 4.000$ dengan presentase yaitu $13 \%$ dan untuk rengginang kerang yaitu dengan upah Rp 4.000 dan presentase 26,31\%.

Tabel 1. Metode Hayami

\begin{tabular}{|c|c|c|c|}
\hline \multicolumn{4}{|c|}{ Analisis Nilai Tambah Metode Hayami } \\
\hline Variabel & No & Sub Variabel & Keterangan \\
\hline \multirow[t]{7}{*}{ Output input dan harga } & 1 & Output & $(1)$ \\
\hline & 2 & Input Bahan Baku & (2) \\
\hline & 3 & Input tenaga kerja & (3) \\
\hline & 4 & Faktor konversi & $(4)=(1):(2)$ \\
\hline & 5 & Koefisien tenaga kerja & $5=(3):(2)$ \\
\hline & 6 & Harga output (Rp) & (6) \\
\hline & 7 & Upah tenaga kerja & $(7)$ \\
\hline \multirow{9}{*}{$\begin{array}{l}\text { Penerimaan dan keun- } \\
\text { tungan }\end{array}$} & 8 & Hargaxinputxbahan baku (Rp/kg) & (8) \\
\hline & 9 & Sumbangan input lain (Rp/kg) & (9) \\
\hline & 10 & Nilai output (Rp/kg) & $(10)=(4) \times(6)$ \\
\hline & 11 & A.Nilai Tambah (Rp/kg) & $(11 a)=(10)-(9)-(8)$ \\
\hline & & B.Rasio nilai tambah Kerja & $(11 b)=(11 a) / 10) \times 100 \%$ \\
\hline & 12 & A. Pendapatan tenaga kerja (Rp/jam) & $(12 a)=(5) \times(7)$ \\
\hline & & B. Pangsa tenaga kerja (\%) & $(12 b)=(12 a / 11 a) \times 100 \%$ \\
\hline & 13. & Keuntungan (Rp/kg) & $(13 a)=11 a-12 a$ \\
\hline & & Tingkat keuntungan (\%) & $(13 b)=(13 a / 11 a) \times 100 \%$ \\
\hline \multirow{4}{*}{$\begin{array}{l}\text { Balas jasa pemilik faktor } \\
\text { produksi }\end{array}$} & 14. & Marjin (Rp/kg) & $(14)=(10)-(8)$ \\
\hline & & Pendapatan tenaga kerja & $(14 a)=(12 a / 14) \times 100 \%$ \\
\hline & & Sumbangan input lain & $(14 b)=(9 / 14) \times 100 \%$ \\
\hline & & Keuntungan perusahaan & $(14 c)=(13 a / 14) \times 100 \%$ \\
\hline
\end{tabular}


Tabel 2. Analisis nilai tambah pada Rengginang Ketan, Teri, Lorjuk dan Kerang

\begin{tabular}{|c|c|c|c|c|c|}
\hline No. & $\begin{array}{l}\text { Analisis Nilai Tambah Metode } \\
\text { Hayami }\end{array}$ & R. Ketan & R. Teri & R. Lorjuk & R. kerang \\
\hline 1. & Output & 18 & 20 & 20 & 20 \\
\hline 2. & Input Bahan baku & 12 & 12 & 12 & 12 \\
\hline 3. & Input Tenaga Kerja & 2 & 2 & 2 & 2 \\
\hline 4. & Faktor Konversi & 1,5 & 1,6 & 1,6 & 1,6 \\
\hline 5. & Koefisien tenaga kerja & 0,16 & 0,16 & 0,16 & 0,16 \\
\hline 6. & Harga Output & 19.000 & 24.000 & 40.000 & 25.000 \\
\hline \multirow[t]{2}{*}{7.} & Upah tenaga kerja & 25.000 & 25.000 & 25.000 & 25.000 \\
\hline & Keuntungan & & & & \\
\hline 8. & Harga input bahan baku & 18.500 & 18.500 & 18.500 & 18.500 \\
\hline 9. & Sumbangan input lain & 4.600 & 10.500 & 14.900 & 6.300 \\
\hline 10. & Nilai Output (4)x(6) & 28.500 & 38.400 & 64.000 & 40.000 \\
\hline \multirow[t]{2}{*}{11.} & a. Nilai Tambah (10)-(9)-(8) & 5.400 & 9.400 & 30.600 & 15.200 \\
\hline & b. Rasio nilai tambah $(11 \mathrm{a} /(10)) \times 100$ & $18,9 \%$ & $24 \%$ & $47 \%$ & $38,75 \%$ \\
\hline \multirow[t]{2}{*}{12.} & a. Pendapatan tenaga kerja (5) $x(7)$ & 4.000 & 4.000 & 4000 & 4000 \\
\hline & b. Pangsa tenaga kerja (12ax11a)x100 & $74 \%$ & $42,5 \%$ & $13 \%$ & $26,31 \%$ \\
\hline \multirow[t]{2}{*}{13} & a. Keuntungan (11a)-(12a) & 1.400 & 5.400 & 26.600 & 11.200 \\
\hline & b. Tingkat keuntungan $(13 a / 11 a) \times 100$ & $25 \%$ & $57,4 \%$ & $86 \%$ & $73 \%$ \\
\hline \multirow[t]{4}{*}{14.} & Margin (10)-(8) & 10.000 & 19.900 & 45.500 & 21.500 \\
\hline & $\begin{array}{l}\text { Pendapatan Tenaga Kerja (12a/14) } \\
\text { x100 }\end{array}$ & $40 \%$ & $20 \%$ & $8,7 \%$ & $18,6 \%$ \\
\hline & Sumbangan input lain(9/14)×100 & $46 \%$ & $52,7 \%$ & $32,27 \%$ & $29 \%$ \\
\hline & Keuntungan $(13 a / 14) \times 100$ & $14 \%$ & $27 \%$ & $58,4 \%$ & $52 \%$ \\
\hline
\end{tabular}

Pada perbandingan 4 rengginang tersebut nilai tambah paling rendah yaitu pada rengginang (tanpa bahan tambahan) karena salah satu faktornya ialah bahan tambahan karena menurut Hayami (1987) dalam Sudiyono (2002) faktor yang memepengaruhi nilai tambah yaitu faktor faktor teknis dan faktor pasar.

Pada faktor pasar antara lain harga output, upah tenaga kerja, harga bahan baku dan nilai input lain. Pada rengginang dinyatakan bahwa harga dari rengginang tanpa bahan tambahan lebih murah dibandingkan dengan rengginang dengan bahan tambahan. Serta input lain dari rengginang tanpa bahan tambahan dibandingan dengan rengginang teri, lorjuk dan kerang memiliki nilai paling rendah. Maka dari itu pengolahan beras ketan menjadi rengginang (teri, lorjuk dan kerang ) memiliki nilai tambah yang lebih tinggi dibandingkan dengan rengginang (tanpa bahan tambahan) dan mampu memberikan keuntungan pada UD. Praktis sehingga perlu adanya inovasi-inovasi terbaru untuk menambah minat konsumen.

Pada analisis nilai tambah diatas pada rengginang ketan, rengginang kerang dan rengginang teri memiliki nilai tambah dan termasuk katgeori sedang karena berada diantara $15 \%-40 \%$ sesuai dengan teori Reyne dalam Hubeis (1997), jika besarnya rasio nilai tambah berada diantara 15\%-40\% maka termasuk kategori sedang jika berada $\geq 40 \%$
Tabel 3. Perbandingan nilai tambah Rengginang ketan, Rengginang teri, Rengginang kerang dan Rengginang Lorjuk

\begin{tabular}{|c|c|c|c|c|}
\hline No. & Jenis Produk & $\begin{array}{l}\text { Nilai } \\
\text { Tambah }\end{array}$ & Rasio & Kategori \\
\hline 1. & $\begin{array}{l}\text { Rengginang } \\
\text { Ketan }\end{array}$ & Rp 5.400 & $18,9 \%$ & $\begin{array}{l}15 \%-40 \% \\
\text { (Sedang) }\end{array}$ \\
\hline 2. & $\begin{array}{l}\text { Rengginang } \\
\text { Teri }\end{array}$ & Rp 9.400 & $24 \%$ & $\begin{array}{c}15 \%-40 \% \\
\text { (Sedang) }\end{array}$ \\
\hline 3. & $\begin{array}{l}\text { Rengginang } \\
\text { kerang }\end{array}$ & Rp 15.200 & $38,75 \%$ & $\begin{array}{c}15 \%-40 \% \\
\text { (Sedang) }\end{array}$ \\
\hline 4. & $\begin{array}{l}\text { Rengginang } \\
\text { Lorjuk }\end{array}$ & Rp 30.600 & $47 \%$ & $\begin{array}{c}\geq 40 \% \\
\text { (tinggi) }\end{array}$ \\
\hline
\end{tabular}

maka termasuk kategori tinggi. dan sejalan dengan penelitian sebelumnya yaitu penelitian Rahman (2015) tentang Ananlisis Nilai Tambah Agroindustri Chips Jagung yang memiliki rasio nilai tambah sebesar $22,6 \%$ hal tersebut menyatakan bahwa rasio nilai tambah termasuk dalam kategori sedang dikarenakan berada di antara 15\%-40\%. Untuk nilai tambah pada rengginang lorjuk yaitu sebesar Rp 30.600 dan termasuk kategori tinggi karena nilai tambah $\geq 40 \%$ dan sejalan dengan penelitian sebelumnya yaitu Artika dan Marini (2016) dengan judul Analisis nilai tambah Buah Pisang Menjadi Keripik Pisang Di Kelurahan Barakan Kota Mataram memperoleh rasio nilai tambah sebesar $81 \%$. 
70 | Maflahah, I. dkk. Analisis Nilai Tambah pada Pengolahan Beras Ketan...

\section{SIMPULAN DAN REKOMENDASI}

Hasil analisis nilai tambah dari produk di UD. Praktis memiliki nilai tambah pada produk rengginang yaitu Rp 5.400, rengginang teri sebesar Rp 9.400, rengginang lorjuk yaitu $\mathrm{Rp} 30.600$ dan rengginang kerang adalah $\mathrm{Rp} 15.200$.

Untuk rengginang ketan memiliki rasio nilai tambah yaitu $18,9 \%$ rengginang teri yaitu $24 \%$, rengginang kerang adalah $38,75 \%$ ketiga rengginang tersebut termasuk kategori sedang karena berada diantara $15 \%-40 \%$ dan rengginang lorjuk yaitu $47 \%$ termasuk kategori tinggi karena memiliki rasio nilai tambah sebesar $\geq 40 \%$.

Perlu dilakuikan promosi dan memperluas daerah pemasaran untuk produk rengginang lorjuk agar mudah dikenal masyarakat dan perlu dilakukan inovasi terhadap rengginang teri agar disukai oleh konsumen.

\section{DAFTAR PUSTAKA}

Artika, I. B.E dan Ida Ayu K.M. (2016). Analisis Nilai Tambah (Value Added) Buah Pisang Menjadi Keripik Pisang Di Kelurahan Babakan Kota Mataram.Vol 10:(1).
Badan Pusat Statistik Provinsi Jawa Timur. (2015). Pendaatan Produksi Beras. Jawa Timur: Badan Pusat Statistik

Badan Pusat Statistik Provinsi Jawa Timur. (2016). Pendataan Sosial Ekonomi.Badan Pusat Statistik

Haryadi. (2006). Teknologi Pengolahan Beras. Yogyakarta : Gadjah Mada University Press

Suryana,A. (1990). Deversifikasi Pertanian Dalam Proses Mempercepat Laju Pengembangan Nasional Pustka Harapan. Jakarta

Hayami Yujiro., Toshiko K.,Yoshinore M and MasjidinS. (1987). Agricultural marketing and processing in upland Java. A perspective from a Sunda village. CGPRT Centre. Bogor.

Hubeis M. (1997). Menuju Industri Kecil Profesional di Era Globalisasi melalui Pember-dayaan Manajemen Industri Orasi Ilmiah Guru Besar Tetap Ilmu Manajemen Industri. Fakultas Teknologi Pertanian. Institut Pertanian Bogor.

Rahman,S. (2015). Analisis Nilai Tambah Agroindustri Chips Jagung. Jurnal Aplikasi Teknologi Pangan.Vol 4:(3). 